\title{
Meta-analysis of relation between cigarette smoking and stroke
}

\author{
Roger Shinton, Gareth Beevers
}

\begin{abstract}
There is a lack of consensus among studies on the possible risks of stroke from cigarette smoking; because of this a meta-analysis was conducted. All published data on the association were sought and the relative risk for each study obtained whenever possible. The pooled relative risks were calculated by using estimates of the precision of the individual relative risks to weight their contribution to the meta-analysis. Thirty two separate studies were analysed. The overall relative risk of stroke associated with cigarette smoking was 1.5 (95\% confidence interval 1.4 to 1.6). Considerable differences were seen in relative risks among the subtypes: cerebral infarction 1.9, cerebral haemorrhage 0.7 , and subarachnoid haemorrhage 2.9. An effect of age on the relative risk was also noted; $<55$ years $2 \cdot 9,55$ 74 years $1 \cdot 8$, and $\geqslant 75$ years $1 \cdot 1$. A dose response between the number of cigarettes smoked and relative risk was noted, and there was a small increased risk in women compared with men. Ex-smokers under the age of 75 seemed to retain an appreciably increased risk of stroke $(1.5)$; for all ages the relative risk in ex-smokers was $1 \cdot 2$.
\end{abstract}

The meta-analysis provides strong evidence of an excess risk of stroke among cigarette smokers. Stroke should therefore be added to the list of diseases related to smoking.

\section{Introduction}

The relation between cigarette smoking and stroke has never been clear cut. Reviews and major textbooks over the past 10 years have considered smoking to be either an unlikely or a possible but uncertain risk factor. ${ }^{1-3}$ Some publications have suggested that it carries a definite risk, but they have tended not to mention the studies that did not support the association. ${ }^{+}$The lack of consensus is not surprising because relative risks of between 0.5 and 3.0 would be expected from existing publications. At these values many studies would give non-significant results or even suggest a reverse association not reflecting the true pattern. This would be especially likely with smaller studies.

If a consensus is to be achieved results of many studies need to be considered together as individual results seem contradictory. For this reason we thought that a meta-analysis (sometimes called an overview) of all available data was worth while. Meta-analyses have been used mainly to improve the power in a series of clinical intervention trials, some of which had reported non-significant trends. ${ }^{5}$ Wald et al, however, used the method to estimate a small increased risk of lung cancer in passive smokers, ${ }^{6}$ and the relative risk of $1 \cdot 3$ in their report has been widely accepted as the best information we have on the issue. We present the results of our meta-analysis on smoking and stroke.

\section{Methods}

\section{CRITERIA FOR SELECTING STUDIES}

The publications reviewed in this analysis all provided information on the relation between cigarette smoking and the incidence of cerebrovascular disease and were epidemiological studies investigating possible risk factors in people rather than populations. Studies that examined the relation by using grouped population data to assess geographical and time trends were not included because they are less able to allow for confounding variables and cannot be conveniently compared with studies on individual people. The studies analysed here, therefore, were both concurrent and historical cohort studies, case-control studies, and intervention trials. In many the association between cigarettes and stroke was not of primary interest but a byproduct of research examining other issues.

Strokes of all descriptions were examined as reliably distinguishing subtypes may be difficult and restricting the investigation to particular subtypes seemed of little value. Also, from the public health point of view which particular subtype of stroke a person suffers is often of only academic interest. Our study, therefore, covered categories 430-438 of the ninth revision of the International Classification of Diseases, though precise definitions varied between the investigations. These categories covered cerebral infarction, cerebral haemorrhage, and subarachnoid haemorrhage.

All reports that fulfilled these criteria were assessed. Although the studies varied in quality, avoiding possible biased selection was easier to achieve by this policy. Nine studies were excluded from the metaanalysis because they did not present data that could be used to derive and weight a relative risk. ${ }^{7 \cdot 14}$

\section{COLLECTING INFORMATION}

Three studies on cigarette smoking and stroke published in widely read medical journals over the past two years were taken as the index references. ${ }^{41516}$ All reports referenced in these three reports were reviewed to assess their eligibility for inclusion. This procedure of cross checking references was continued until no new studies were identified. Studies published after 1 May 1988 were not included.

Additional references were sought by using a Medline computer search with cigarette smoking, cerebral infarction, cerebral haemorrhage, subarachnoid haemorrhage, and cerebrovascular disorders as key words. A search back to 1965 identified only four further publications that met the criteria for entry. Care was taken to ensure that only one publication from each survey was included in the analysis. When there were several papers based on a single project the most recent was used. The following details were collected from each publication: name of study, design, subtypes of stroke assessed, population characteristics (for example, sex and age range), methods of dealing with confounding variables, and all data on the association between cigarette smoking and stroke. In one large study (British doctors) the authors were approached and supplied data not available in the original publications. ${ }^{17} 18$ We thought it impracticable, however, to approach all authors for data not available in their publications.

\section{MEASURES OF RISK CHOSEN FOR META-ANALYSIS}

The principal measure of risk chosen for this study 


\begin{tabular}{|c|c|c|c|c|c|}
\hline Name and details of study & $\begin{array}{l}\text { Total No } \\
\text { of strokes }\end{array}$ & $\begin{array}{l}\text { Derivation } \\
\text { of relative } \\
\text { risk }\end{array}$ & $\begin{array}{l}\text { Relative } \\
\text { risk }\end{array}$ & $\begin{array}{l}\text { Method of } \\
\text { estimating } \\
\text { variance of } \\
\text { relative } \\
\text { risk }\end{array}$ & $\begin{array}{l}\text { Data available for } \\
\text { subgroup analysis }\end{array}$ \\
\hline & & Coh & udies & & \\
\hline Cancer society:: & 3313 & Quoted in study & & * & Sex, age, dose \\
\hline Men 45-54 years & & & 1.50 & & \\
\hline Men 55-64 years & & & 1.41 & & \\
\hline Men $65-74$ years & & & $1 \cdot 37$ & & \\
\hline Men $75-84$ years & & & $0 \cdot 86$ & & \\
\hline Women $45-54$ years & & & $2 \cdot 11$ & & \\
\hline Women $55-64$ years & & & 1.54 & & \\
\hline Women 65-74 years & & & $1 \cdot 38$ & & \\
\hline Women $75-84$ years & & & $1 \cdot 18$ & & \\
\hline Veterans $^{23}$ & 1515 & Quoted in study & 1.52 & $\star$ & Sex, age, dose, ex-smoker \\
\hline Washington county ${ }^{i+}$ & 926 & Quoted in study & & ${ }^{\star} \dagger$ & Subtype of stroke, sex, dose \\
\hline Mortality & & & 0.85 & & \\
\hline Men, morbidity & & & 0.90 & & \\
\hline Women, morbidity & & & 0.92 & & \\
\hline British doctors ${ }^{1-1 x}$ & 470 & Rate ratio $\ddagger$ & & * & Subtype of stroke, sex, age, dose, ex-smoker \\
\hline Men & & & $1 \cdot 34$ & & \\
\hline Women, $1-14$ cigarettes/day & & & 0.93 & & \\
\hline Women, 15-24 cigarettes/day & & & 0.45 & & \\
\hline Women, $\geqslant 25$ cigarettes/day & & & $0 \cdot 19$ & & \\
\hline Framingham $" *$ & 459 & Quoted in study & & $\star 5$ & Subtype of stroke, sex \\
\hline Men & & & $1 \cdot 21$ & & \\
\hline Women & & & $1 \cdot 30$ & & \\
\hline Honolulu ${ }^{2 h}$ & 288 & Quoted in study & $2 \cdot 1$ & $\star$ & Subtype of stroke, sex, age, dose, ex-smoker \\
\hline Nurses $^{16}$ & 274 & Quoted in study & & * & Subtype of stroke, sex, age, dose, ex-smoker \\
\hline 1-14 Cigarettes/day & & & $2 \cdot 2$ & & \\
\hline 15-24 Cigarettes/day & & & $2 \cdot 7$ & & \\
\hline$>25$ Cigarettes/day & & & $3 \cdot 7$ & & \\
\hline Alumni & 273 & Quoted in study & & $\star \mathbb{S}$ & Sex, age, dose \\
\hline $\begin{array}{l}\text { Mortality } \\
\text { Morbidity }\end{array}$ & & & $2 \cdot 1$ & & \\
\hline $\begin{array}{l}\text { Morbidity } \\
\text { Chicago }^{: 0}\end{array}$ & 187 & & 1.57 & $\star$ & Dose, ex-smoker \\
\hline $\begin{array}{l}\text { Chicago } \\
1-9 \text { Cigarettes/day }\end{array}$ & 101 & Risk ratio| & $1 \cdot 29$ & & Dose, ex-smoker \\
\hline 10-19 Cigarettes/day & & & 0.85 & & \\
\hline$\geqslant 20$ Cigarettes/day & & & 0.81 & & \\
\hline Japanese doctors $s^{4 \prime}$ & 154 & Quoted in study & $1 \cdot 42$ & ^ & Sex, dose, ex-smoker \\
\hline North Karelia" & 128 & Quoted in study & & $t$ & Subtype of stroke, sex \\
\hline Men, cerebral infarction & & & $4 \cdot 2$ & & \\
\hline Men, other strokes & & & $2 \cdot 2$ & & \\
\hline Women, cerebral infarction & & & $1 \cdot 4$ & & \\
\hline Women, other strokes & & & 0.8 & & \\
\hline Akabane/Asali ${ }^{22}$ & 121 & Quoted in study & & * & Subtype of stroke, dose \\
\hline Cerebral haemorrhage, & & & & & \\
\hline $\begin{array}{l}\text { 1-9 cigarettes/day } \\
\text { Cerebral haemorrhage, }\end{array}$ & & & 1.9 & & \\
\hline $10-19$ cigarettes/day & & & $1 \cdot 5$ & & \\
\hline $\begin{array}{l}\text { Cerebral haemorrhage, } \\
\geqslant 20 \text { cigarettes/day }\end{array}$ & & & & & \\
\hline $\begin{array}{l}\geqslant 20 \text { cigarettes/day } \\
\text { Cerebral thrombosis, }\end{array}$ & & & $1 \cdot 2$ & & \\
\hline $\begin{array}{l}\text { Cerebral thrombosis, } \\
1-9 \text { cigarettes/day }\end{array}$ & & & $2 \cdot 7$ & & \\
\hline $\begin{array}{l}1-9 \text { cigarettes/day } \\
\text { Cerebral thrombosis, }\end{array}$ & & & & & \\
\hline $\begin{array}{l}\text { Cerebral thrombosis, } \\
10-19 \text { cigarettes/day }\end{array}$ & & & 1.9 & & \\
\hline $\begin{array}{l}10-19 \text { cigarettes/day } \\
\text { Cerebral thrombosis, }\end{array}$ & & & & & \\
\hline$\geqslant 20$ cigarettes/day & & $"$ & $2 \cdot 4$ & & \\
\hline Longshoremen" & 112 & Quoted in study & 1.03 & * & Subtype of stroke, sex, dose \\
\hline Whitehail $^{4}$ & 91 & Risk ratio & & * & Sex, dose, ex-smoker \\
\hline 1-9 Cigarettes/day & & & $1 \cdot 0$ & & \\
\hline 10-19 Cigarettes/day & & & $2 \cdot 0$ & & \\
\hline$\geqslant 20$ Cigarettes/day & & & $2 \cdot 3$ & & \\
\hline California elderly patients" & 73 & Risk ratio & & ^ & Sex, ex-smoker \\
\hline Men & & & 1.72 & & \\
\hline Women & & & 1.88 & & \\
\hline Oxford Family Planning Association ${ }^{\text {th }}$ & 38 & Rate ratio $\ddagger$ & & * & Subtype of stroke, sex, age, ex-smoker \\
\hline Subarachnoid haemorrhage & & & $3 \cdot 0$ & & \\
\hline $\begin{array}{l}\text { Non-haemorrhagic stroke } \\
\text { Contraception cohort }\end{array}$ & & & $1 \cdot 36$ & $t$ & \\
\hline & 34 & Quoted in study & $5 \cdot 7$ & 1 & Subtype of stroke, sex, age \\
\hline $\begin{array}{l}\text { Subarachnoid haemorrhage } \\
\text { Other strokes }\end{array}$ & & & $4 \cdot 8$ & & \\
\hline & & Case-contro & & & \\
\hline Cigarette type $^{3 x}$ & 824 & Quoted in study & & $\oint$ & Sex \\
\hline Men, handrolled & & & 1.03 & & \\
\hline Men, manufactured and handrolled & & & 1.06 & & \\
\hline Men, manufactured & & & 1.05 & & \\
\hline Women, manufactured & & & $1 \cdot 10$ & & \\
\hline Canada case-control ${ }^{99}$ & 606 & Odds ratio & $2 \cdot 17$ & $\star \star$ & Subtype of stroke \\
\hline Neurological hospitals ${ }^{t+1}$ & 504 & Odds ratio & & 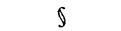 & Subtype of stroke, sex, ex-smoker \\
\hline Subarachnoid haemorrhage & & & $2 \cdot 44$ & & \\
\hline Other strokes & & & 0.66 & & \\
\hline New Zealand ${ }^{1+2}$ & 247 & Quoted in study & & st & Subtype of stroke, sex, dose, ex-smoker \\
\hline Subarachnoid haemorrhage & & & $3 \cdot 8$ & & \\
\hline Other strokes & & & 2.9 & & \\
\hline Helsinkit3 & 211 & Odds ratiof & $4 \cdot 16$ & @ & Subtype of stroke, sex, age \\
\hline Central Middlesex ${ }^{\star}$ & 178 & Odds ratiof & 1.99 & ఏ & Subtype of stroke, sex, ex-smoker \\
\hline Tilberg & 126 & Quoted in study & $1 \cdot 2$ & $\S$ & Dose \\
\hline Central Finland & 114 & Odds ratio & $2 \cdot 79$ & $\star \star$ & Subtype of stroke, sex \\
\hline New York elderly patients & 101 & Odds ratiof & $2 \cdot 11$ & $\int$ & Subtype of stroke, sex, dose \\
\hline Glasgow $^{+4}$ & 88 & Odds ratiof & 3.44 & $\int$ & Subtype of stroke, sex, dose \\
\hline Helsinki case-control ${ }^{49}$ & 54 & Quoted in study & $2 \cdot 0$ & $t$ & Subtype of stroke, sex, age, dose \\
\hline Illinois ${ }^{\omega}$ & 44 & Quoted in study & & $t$ & Subtype of stroke, sex, age \\
\hline Men & & & $1 \cdot 15$ & & \\
\hline Women & & & $4 \cdot 30$ & & \\
\hline San Diego" & 40 & Quoted in study & $1 \cdot 76$ & $t$ & \\
\hline Boston drug survey ${ }^{52}$ & 14 & Odds ratiof & $1 \cdot 43$ & $\$$ & Sex, age \\
\hline & & Interventi & & & \\
\hline Medical Research Council & & & & & \\
\hline Hypertension ${ }^{43}$ & 169 & Quoted in study & $2 \cdot 29$ & $\dagger$ & \\
\hline
\end{tabular}


was the relative risk of stroke among cigarette smokers compared with non-smokers. This was the only measure that could be obtained from both cohort and case-control studies and thus enabled the maximum number of publications to be included. A potential problem with the use of relative risk is that it covers the rate ratio, risk ratio, and odds ratio. As stroke is fairly rare, however, the differences between these ratios are minimal. If a publication enabled more than one measure of relative risk to be derived the order of preference was rate ratio, risk ratio, and odds ratio. The principal estimates presented were the age adjusted, multiple risk factor adjusted, or crude relative risks; when more than one of these was available preference was in that order, mainly because the age adjusted relative risks were most commonly available and thus the most appropriate to compare. Crude rates were the least popular because of the likely confounding effect of age, which is associated with both the risk of stroke and cigarette smoking. When relative risks were not provided they could, in many instances, be derived (see table I for methods used).

When alternative definitions of cigarette smokers were available the preferred option was those currently smoking only cigarettes. The preferred definition of non-smokers was those who had never smoked. Exsmokers were investigated separately. For each study and each variable of interest within a study an attempt was made to provide a summary relative risk. This was not possible sometimes because of the form in which the data were provided. In these cases the smallest series of separate relative risks that covered all the data were selected. For example, if relative risks by both three age groups and four levels of cigarette smoking were available the risks by age groups were chosen to represent the study.

\section{METHOD OF POOLING AND WEIGHTING DIFFERENT ESTIMATES OF RELATIVE RISK}

The estimates of relative risk were all transformed to their natural logarithm before pooling. The distribution of the natural logarithm of the relative risk is closer to normal than that of the untransformed value. After pooling we transformed the natural logarithm of the relative risk to its antilogarithm for presentation.

When we pooled the relative risks of different studies we weighted the relative risk from studies according to the precision of the estimate. The method adopted for weighting entailed calculating the inverse of the variance of the natural logarithm of the relative risk. ${ }^{19}$ In cohort studies the variance of the natural logarithm of the rate ratio can be approximated to $1 /$ exposed cases $+1 /$ unexposed cases. ${ }^{20}$ The same approximation is not unreasonable for risk ratios when the denominator is far larger than the number of cases. In case-control studies the variance of the natural logarithm of the odds ratio is 1/exposed cases $+1 /$ unexposed cases +1 /exposed controls $+1 /$ unexposed controls. ${ }^{20}$ In matched studies an estimate of the variance of the natural logarithm of the odds ratio is calculated from discordant pair data: 1/exposed cases matched with unexposed controls +1 /exposed controls matched with unexposed cases. ${ }^{20}$ If the above data

TABLE II-Estimated relative risk of stroke in cigarette smokers compared with non-smokers by subtype of stroke

\begin{tabular}{lcc}
\hline Subtype of stroke & $\begin{array}{c}\text { No of } \\
\text { estimates } \\
\text { analysed }\end{array}$ & $\begin{array}{c}\text { Pooled relative } \\
\text { risk }(95 \% \\
\text { confidence interval) }\end{array}$ \\
\hline Cerebral infarction & 22 & $1.92(1.71$ to 2.16$)$ \\
$\begin{array}{l}\text { Haemorrhagic stroke } \\
\begin{array}{l}\text { Intracerebral haemorrhage (excluding } \\
\text { subarachnoid haemorrhage) }\end{array}\end{array}$ & 7 & $1.01(0.81$ to 1.26$)$ \\
\begin{tabular}{l} 
Subarachnoid haemorrhage \\
\hline
\end{tabular} & 10 & $\begin{array}{l}0.74(0.56 \text { to } 0.98) \\
2.93(2.48 \text { to } 3.46)\end{array}$ \\
\hline
\end{tabular}

were not available the variance could be derived from confidence intervals provided ${ }^{21}$ (see table I for the different methods of weighting used in each study).

The weights obtained from the inverse of the variance of the natural logarithm of the relative risk were used to estimate confidence intervals. The variance of the pooled natural logarithm of the relative risk is $1 /$ sum of individual natural logarithms of the relative risk weights. ${ }^{19}$ Confidence intervals were presented after antilogarithmic transformation.

\section{Results}

Table I gives details of the 32 projects in 36 publications that were analysed. Seventeen of these studies were cohort studies, 14 case-control studies, and one a hypertension intervention trial. In 19 of the 32 studies estimates of relative risk were available (table I), but only eight included a relative risk that summarised the whole study. Studies that presented separate estimates of relative risk were subdivided by a range of variables: age, sex, subtype of stroke, number and type of cigarettes smoked, and mortality and morbidity.

\section{ALL STROKES AND ALL CIGARETTE SMOKING}

The survey yielded 69 separate estimates of relative risk. These ranged widely, from $0 \cdot 19$ to $5 \cdot 7$, but increased in stability as the size of each study increased - that is, 0.66 to $4 \cdot 16$ for studies with 100 or more strokes and 0.85 to 2.44 for studies with over 500 cases. The estimated overall relative risk of stroke for cigarette smoking was 1.51 (95\% confidence interval 1.45 to $1 \cdot 58$ ). Even after the number of cases of stroke on which each relative risk was based was used to weight the data when the relative risk was pooled, the results remained $1 \cdot 5$.

\section{Stroke risk by subtype of stroke}

Before this meta-analysis there was general agreement that cigarette smoking was associated with subarachnoid haemorrhage. We thought it important, therefore, to examine the possibility that cigarettes cause subarachnoid haemorrhage but not other subtypes of stroke. If this were so the positive association seen with subarachnoid haemorrhage would produce a much diluted positive association for all strokes combined. As subarachnoid haemorrhage can usually be distinguished clinically from other subtypes of stroke we examined all the data on stroke excluding cases diagnosed as subarachnoid haemorrhage. The weighted, pooled relative risk after we excluded subarachnoid haemorrhage in 35 separate relative risk estimates was 1.43 (95\% confidence interval 1.33 to $1 \cdot 55)$.

We investigated the risks for cigarette smoking in the three main subtypes. The diagnosis of cerebral infarction included both cerebral thrombosis and cerebral embolism as distinguishing the two is often impossible. Within the subtype cerebral haemorrhage were included some studies in which the stroke was defined as haemorrhagic and possibly also included a small proportion of subarachnoid haemorrhages. ${ }^{26} 3339$ An estimate that excluded these studies was also performed. Those strokes grouped as subarachnoid haemorrhages in the analysis included all the pathological types - that is, aneurysmal, arteriovenous malformation, or primary (origin unknown).

Table II shows data that suggest that there are differences in the relative risks for cigarette smokers between the subtypes. Subarachnoid haemorrhage was clearly associated with cigarette smoking, and cerebral infarction was almost twice as likely in cigarette smokers as non-smokers. The results for cerebral 
haemorrhage did not show any clear association. The relative risk of cerebral haemorrhage was strongly influenced by a single study (neurological hospitals) with a relative risk considerably less than $1 \cdot 0 .{ }^{41}$

RISK BY SEX, AGE, AND NUMBER OF CIGARETTES SMOKED

When data were subdivided by sex they were analysed separately. The results (table III) indicated a small difference in relative risks between the sexes with pooled relative risks of 1.43 and 1.72 for men and women respectively. To examine this apparent difference further we restricted the analysis to more immediately comparable data - that is, studies of both men and women. This analysis produced similar results with relative risks of 1.32 and 1.56 for men and women respectively.

Studies that presented data within only selected age bands were included in the analysis of relative risk by age. A clear trend was seen in relative risk as the age at the time of stroke increased (table III). The relative risk of 2.9 in those aged under 55 was unchanged when the subarachnoid haemorrhage study (Oxford Family Planning Association) was excluded. ${ }^{36}$ No large study has ever shown anything other than a positive association between cigarette smoking and stroke in people aged under 75. Large studies, however, have on several occasions indicated little or even a negative association in elderly people.

To determine the relative risk of stroke by the number of cigarettes smoked the data were grouped into three categories: low consumption-mainly less than 10 cigarettes a day; intermediate - mainly between 10 and 20 cigarettes a day; and high -20 or more cigarettes a day. The pooled relative risk estimates indicated a dose response from 1.37 in light smokers to 1.82 in heavy smokers (table III).

TABLE III-Estimated relative risk of stroke in cigarette smoker compured with non-smokers by sex, age, and number of cigarette smoked

\begin{tabular}{|c|c|c|}
\hline Variable & $\begin{array}{l}\text { No of } \\
\text { estimates } \\
\text { analysed }\end{array}$ & $\begin{array}{c}\text { Pooled relative } \\
\text { risk ( } 95 \% \\
\text { confidence interval) }\end{array}$ \\
\hline \multicolumn{3}{|l|}{ Sex: } \\
\hline Men & 32 & $1.43(1.35$ to 1.52$)$ \\
\hline Women & 31 & $1.72(1.59$ to 1.86$)$ \\
\hline \multicolumn{3}{|r|}{ 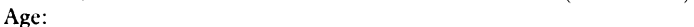 } \\
\hline$<55$ & 11 & $2.94(2.40$ to 3.59$)$ \\
\hline $55-74$ & 8 & $1.75(1.56$ to 1.97$)$ \\
\hline$\geqslant 75$ & 6 & $1.11(0.96$ to 1.28$)$ \\
\hline \multicolumn{3}{|l|}{ Cigarettes/day: } \\
\hline Low (mainly $<10$ ) & 21 & $1.37(1.24$ to 1.52$)$ \\
\hline Intermediate (mainly 10-20) & 20 & $1.45(1.33$ to 1.57$)$ \\
\hline $\operatorname{High}(>20)$ & 33 & $1.82(1.70$ to 1.96$)$ \\
\hline
\end{tabular}

\section{EX-SMOKERS AND STROKE}

The pooled relative risk associated with being an exsmoker derived from 18 separate relative risk estimates was somewhat increased at $1 \cdot 17$ (95\% confidence interval $1 \cdot 05$ to $1 \cdot 30$ ). This relative risk increased to $1.47(1.15$ to 1.88$)$ when the studies included were restricted to those with patients who suffered their stroke when under the age of $75 . .^{15} 163436$

\section{ASSESSMENT OF THE INFLUENCE OF POSSIBLE} CONFOUNDING VARIABLES

In all studies confounding by age was dealt with by age adjustment, matching, or restriction of the age group studied. As cigarette consumption is only weakly linked to age it seems unlikely that any residual confounding by age could have produced the observed association.

Blood pressure and possibly obesity are risk factors for stroke and also may be influenced by smoking. Most evidence suggests that cigarette smokers are thinner and have lower blood pressures than non- smokers. Almost certainly smoking causes these changes in blood pressure and weight. This suggests that adjustment for blood pressure or weight may overestimate the risks from cigarette smoking. This increase in the relative risk was seen in all the eight relative risk results from four studies (table IV). When pooled the relative risks adjusted for age and blood pressure or obesity, or both, were substantially higher than those adjusted for age alone.

TABLE IV-Relative risk of stroke in cigarette smokers compared with non-smokers adjusted for age and for age, blood pressure, and obesity

\begin{tabular}{|c|c|c|c|}
\hline \multirow[b]{2}{*}{ Name and details of study } & \multirow[b]{2}{*}{$\begin{array}{l}\text { No of } \\
\text { strokes }\end{array}$} & \multicolumn{2}{|c|}{ Relative risk adjusted by } \\
\hline & & Age & $\begin{array}{l}\text { Age, blood } \\
\text { pressure, and } \\
\text { obesity }\end{array}$ \\
\hline \multicolumn{4}{|l|}{ Framingham: } \\
\hline Men & 221 & $1 \cdot 21$ & $2 \cdot 2$ \\
\hline Women & 238 & $1 \cdot 30$ & $2 \cdot 5$ \\
\hline Honolulu & 288 & $2 \cdot 10$ & $2 \cdot 5$ \\
\hline \multicolumn{4}{|l|}{ Nurses: } \\
\hline 1-14 Cigarettes/day & 110 & $2 \cdot 20$ & $2 \cdot 5$ \\
\hline 15-24 Cigarettes/day & 126 & $2 \cdot 70$ & $2 \cdot 9$ \\
\hline$\geqslant 25$ Cigarettes/day & 123 & $3 \cdot 70$ & $3 \cdot 8$ \\
\hline \multicolumn{4}{|l|}{ California elderly patients: } \\
\hline Men & 39 & $1 \cdot 72$ & $2 \cdot 0$ \\
\hline Women & 34 & $1 \cdot 88$ & $3 \cdot 9$ \\
\hline $\begin{array}{l}\text { Pooled total }(95 \% \\
\text { confidence interval) }\end{array}$ & & $\begin{array}{l}1 \cdot 9(1 \cdot 6 \\
\text { to } 2 \cdot 1)\end{array}$ & $\begin{array}{l}2 \cdot 6(2 \cdot 3 \\
\text { to } 2 \cdot 9)\end{array}$ \\
\hline
\end{tabular}

Alcohol consumption has been linked to stroke in some but not all investigations..$^{54}$ Excessive alcohol consumption is associated with cigarette smoking. ${ }^{55}$ Table $\mathrm{V}$ presents those studies that measured alcohol consumption and adjusted for it in the analysis. The association of stroke with cigarette smoking seemed to remain after adjustment for alcohol consumption; indeed, adjustment in these studies tended not to reduce the relative risk, which suggests that alcohol consumption is not an important confounding variable. Furthermore, the excess risk in women compared with men argues strongly against the possibility that the relation between stroke and cigarette smoking is the result of the confounding effect of alcohol.

TABLE $\mathrm{v}-$ Relative risk of stroke in cigarette smokers compared with non-smokers in studies that adjusted for alcohol intake

\begin{tabular}{lcc}
\hline Name and details of study & No of strokes & $\begin{array}{c}\text { Relative risk } \\
\text { (95\% confidence interval) }\end{array}$ \\
\hline $\begin{array}{l}\text { Honolulu } \\
\text { Illinois: }\end{array} \quad 288$ & $2 \cdot 50(2 \cdot 0$ to $3 \cdot 3)$ \\
$\quad$ Men & 25 & $1.03(0 \cdot 72$ to 1.48$)$ \\
$\quad$ Women & 29 & $3.88(1 \cdot 79$ to $8 \cdot 41)$ \\
Helsinki case-control & 54 & $2.00(0.5$ to $7 \cdot 5)$ \\
\hline$\quad$ Pooled total & & $2 \cdot 4(1.9$ to $2 \cdot 9)$
\end{tabular}

\section{ASSESSMENT OF POSSIBLE PUBLICATION BIAS}

We assessed the possibility that the selective publication of studies indicating a positive association might produce a misleading picture. Figure 1 plots the relative risk against the number of strokes on which the relative risk was based. Publication bias would be suspected if there was a deficit of estimates in small studies which were around or below $1 \cdot 0$. We would expect the larger studies to lie closer to the marked "true" value shown by the vertical broken line. Although the spread of points was not entirely even the pattern still suggested that there was an association between cigarette smoking and stroke. The most likely explanation for this uneven pattern is that larger studies tend to include many older patients, who seem to have a lower relative risk. Figure 2 , which plots only strokes in patients aged under 55 , is more evenly distributed and would support this explanation.

As large studies are almost always published the 


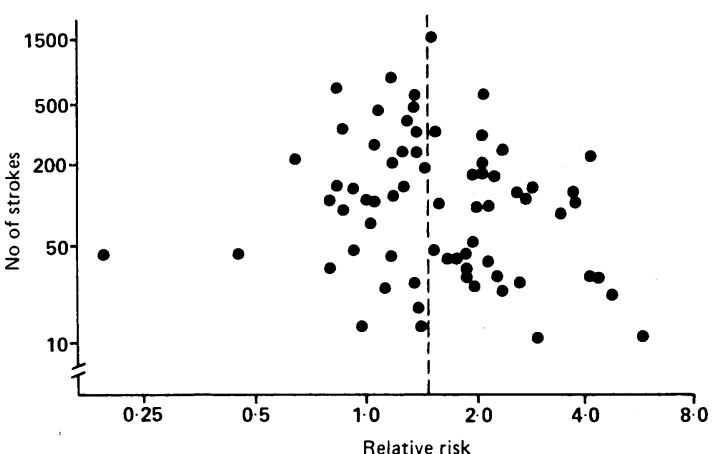

FIG 1 -Relative risk plotted against number of strokes in study for all data on relation between stroke and cigarette smoking (broken line shows overall value )

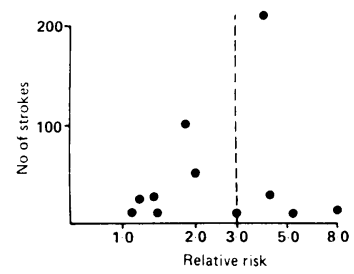

FIG 2-Relative risk plotted against number of strokes in study for data on relation between stroke and cigarette smoking in patients aged under 55

scope for publication bias among them is reduced. The relative risk for studies with more than 500 cases was $1 \cdot 3$, with more than 100 cases $1 \cdot 5$, and with more than

\section{Discussion}

The results of this meta-analysis provide strong evidence of the excess risk of stroke among cigarette smokers. Stroke should, therefore, be firmly added to the list of diseases related to smoking. The overall 50 cases $1 \cdot 5$. excess relative risk of $50 \%$ is modest by epidemiological standards but reflects a large potential for preventing stroke. Neither publication bias nor the confounding effects of age, obesity, blood pressure, or alcohol seemed to account for the findings. The dose response noted adds further weight to the case against cigarettes. In view of the increased risk among ex-smokers smoking probably causes strokes principally through structural damage to the arterial walls of an atheromatous nature. Structural damage of an aneurysmal form may well be responsible for causing subarachnoid haemorrhages.

The meta-analysis allowed examination of the variation in the risks of cigarette smoking by subtype of stroke, sex, age, and number of cigarettes smoked. Not unexpectedly, large differences in the risk were found with some variables. Subarachnoid haemorrhage was considerably more common among smokers than nonsmokers - all studies showed an excess risk - but other strokes also seemed to be related to smoking. The increased risk of cerebral infarction was not surprising in view of the well established dangers of cigarette smoking for other atherosclerotic disorders-namely, heart attacks and peripheral vascular disease. This study did not, however, confirm smoking as a cause of cerebral haemorrhage, but any adverse or beneficial effect of cigarettes for this condition is small. Considerably more data and better diagnosis with computed tomography will be required for the picture to become clearer.

A small difference was seen between the sexes with a greater risk for women. A recent analysis of the Medical Research Council's trial on mild hypertension suggested significantly greater risks of cardiovascular disease related to stroke in women. ${ }^{56}$ These are fairly new findings and have implications for health promotion strategies. Reasons for the differences are speculative and may include a higher dose per unit of body mass from a single cigarette in women, the concurrent use of oral contraceptives, and even a small protective effect of the widespread use of alcohol in men who smoke.

One of the most striking findings from this metaanalysis was the changing relative risk with age. The risks of stroke associated with smoking are apparently present in all age groups but are far greater in younger people. In those publications that provided data stratified by age the trend was for a decreasing relative risk with age. This finding may explain the inconsistencies seen among studies. Coronary heart disease seems to have a similar pattern of falling relative risk for smoking with age. ${ }^{17}$ The explanation for this effect is not clear but may be that similar differences in risk produce more distinct relative risk values in the young when the disease is rare. An additional contributory factor may be less accurate diagnosis in older patients, producing an apparent dilution of any true effect. Old smokers may also be more cautious or lighter smokers with consequently reduced risks.

The increased risks of stroke of ex-smokers, when noted, have usually been considered unlikely..$^{416}$ The meta-analysis suggests that ex-smokers have around a $50 \%$ increased risk of suffering a stroke before the age of 75 . The possibility that some people who reported themselves as ex-smokers were in reality current smokers cannot be dismissed. The diminishing relative risk with age was again apparent in ex-cigarette smokers.

Examination of adjusting for obesity or blood pressure, or both, on the relative risk of stroke associated with cigarette smoking produced a distinct effect: the adjustment seemed to increase the relative risk. As cigarette smoking seems to lower weight and blood pressure the adjustment might seem unreasonably to overestimate the effect of smoking. Possibly in the Framingham study the value adjusted for blood pressure was presented because it was significantly higher, whereas the value adjusted for age, though higher, failed to reach the required $p$ value of $0.05 .^{4}$

All the above conclusions depend on an acceptance of the validity of meta-analysis. The principal criticism is that studies and populations that are clearly different are being grouped together on the assumption that they are similar. Even within many individual studies, however, groups that are likely to differ substantially have been combined so the same problems apply to both individual studies and combined results. An advantage of meta-analysis is that it allows examination of subgroups when individual studies have inadequate numbers. While different studies have used different methods - for example, questionnaires - it seems unlikely that differences in detecting cigarette smokers would have introduced any serious errors or altered the conclusions.

We thank Ms Lucy Carpenter for advice on statistical methods for epidemiology; Mrs Julie Evans for providing a Medline computer search; Mrs Dilys Thomas, who produced the figures; and Mr Richard Gray, who provided data from the British doctors cohort.

1 Dyken ML, Wolf PA, Barnett HJM, et al. Risk factors in stroke: a statement for physicians by the sub-committee on risk factors and stroke of the stroke council. Stroke 1984;15:1105-11.

2 Warlow CP. Cerebrovascular disease. In: Weatherall DJ, Ledingham JGG, Warrell DA, eds. Oxford textbook of medicine. Oxford: Oxford University Press, 1987:21.155.

3 Ostfeld AM. A review of stroke epidemiology. Epidemiol Rev 1980;2:136-52.

4 Wolf PA, D'Agostino RB, Kannel WB, Bonita R, Belanger AJ. Cigarette smoking as a risk factor for stroke. JAMA 1988;259:1025-9.

5 Yusuf S, Peto R, Lewis J, Collins R, Sleight P. Beta blockade during and after myocardial infarction: an overview of the randomised trials. Prog Cardiovasc myocardial infarction:

6 Wald NJ, Nanchackal K, Thompson SG, et al. Does breathing other people's tobacco smoke cause lung cancer? Br Med $f$ 1986;293:1217-22.

7 Johnson KG, Yano K, Kato H. Cerebral vascular disease in Hiroshima, Japan. Japanese fournal of Chronic Disease 1967;20:545-59.

8 Kiyohara Y, Ueda K, Hasuo Y, et al. Hematocrit as a risk factor of cerebral infarction: long-term prospective population survey in a Japanese rural community. Stroke 1986;17:687-92.

9 Welin L, Svardsudd K, Wilhelmsen L, Larsson B, Tibblin G. Analysis of risk factors for stroke in a cohort of men born in 1913. N Engl $\mathcal{f}$ Med 1987;317:521-6.

10 Royal College of General Practitioners Oral Contraceptive Study. Further analyses of morality in oral contraceptive users. Lancet 1981;i:541-6.

11 Collaborative Group for Study of Stroke in Young Women. Oral contraception and increased risk of cerebral ischemia or thrombosis. $N$ Engl J Med and increased $1973 ; 288: 871-8$.

12 Stallones RA, Dyken ML, Fang HCH, Heyman A, Seltser R, Stamler J. Epidemiology for stroke facilities planning. Stroke 1972;3:360-71. 
13 International Prospective Primary Prevention Study in Hypertension Collaborative Group. Cardiovascular risk and risk factors in a randomized trial of treatment hased on the beta-blocker oxprenolol. I Hypertens 1985;3 $379-92$

14 Tanaka $\mathrm{H}$, Veda Y, Hayashi $M$, et al. Risk factors for cerebral hemorrhage and cerebral infarction in a Japanese rural community. Stroke 1982;13:62-73.

15 Bonita R, Scragg R, Stewart A, Jackson R, Beaglehole R. Cigarette smoking and risk of premature stroke in men and women. $\mathrm{Br} \mathrm{Med} \mathcal{f}$ 1986;293:6-8.

16 Colditz GA, Bonita R, Stampfer MJ, et al. Cigarette smoking and risk of stroke in middle-aged women. $N$ Engl F Med 1988;318:937-41.

17 Doll R, Peto R. Mortality in relation to smoking: 20 years' observations on male British doctors. Br.Med f 1976;ii:1525-36.

18 Doll R, Gray R, Hafner B, Peto R. Mortality in relation to smoking: 22 years observations on female British doctors. Br Med F 1980;280:967-71.

19 Armitage P. Berry G. Statistical methods in medical research. Oxford: Blackwell Scientific, 1987.

20 Rothman KJ. Modern epidemiology. Boston: Little, Brown, 1987.

21 Vandenbroucke JP. Passive smoking and lung cancer: a publication bias? Br.Med f 1988;296:391-2.

22 Hammond EC. Smoking in relation to the death rates of one million men and women. In: Haenszel W' ed. Epidemiological approaches to the study of cancer and other chronic diseases. Bethesda: United States Department of Health Education and Welfare, Public Health Service, 1966:127-204. (National Cancer Institute Monograph No 19

23 Khan HA. The Dorn study of smoking and mortality among US veterans: report on eight and one half years of observation. In: Haenszel W, ed. Epidemiological approaches to the study of cancer and other chronic diseuses. Bethesda: United States Department of Health, Education and Welfare, Public Health Service, 1966:1-126. (National Cancer Institute Monograph No 19 .

24 Nomura A, Comstock GN, Kuller L, Tonascia JA. Cigarette smoking and strokes. Stroke 1974;5:483-6.

25 Sacco RL Wolf PA, Bharucha NE ot al Sub-arachnoid and intracerebral hemorrhage: natural history, prognosis and precursive factors in the Framingham study. Neurology 1984;34:847-54

26 Abbott RD, Yin Yin MA, Reed DM, Yano K. Risk of stroke in male cigarette smokers. N Eingl f Med 1986;315:717-20.

27 Paffenbarger RS, Wing AL. Chronic disease in former college students: early precursors of non-fatal stroke. Am J Epidemol 1971;94:524-30.

28 Paffenbarger RS, Wing AL. Characteristics in youth predisposing to fatal stroke in later years. Lancet 1967; i:753-4.

29 Ostfeld AM, Shekelle RB, Klawans H, Tufo HM. Epidemiology of stroke in an elderly welfare population. Am f Public Health 1974;64:450-8.

30 Kono $S$, Ikeda $M$, Tokudome $S$, Nishizumi $M$, Kuratsune $M$. Smoking and mortalities from cancer, coronary heart disease, and stroke in male Japanese physicians. F Cancer Clin Oncol 1985;110:161-4.

31 Salonen JT, Puska P, Tuomilehto J, Homan K. Relation of blood pressure, serum lipids, and smoking to the risk of cerebral stroke. A longitudinal study in eastern Finland. Stroke 1982;13:327-33.

32 Okada $M$, Horibe M, Ohno Y, Hayakawa N, Oaki N. A prospective study of cerebrovascular disease in Japanese rural communities, Akabane and Asali. Stroke 1976;6:599-607.

33 Paffenbarger RS, Brand RJ, Sholtz RJ, Jung DL. Energy expenditure, cigarette smoking, and blood pressure level as related to death from specitic diseases. Am f Epidemiol 1978;108:12-8.

34 Fuller JH, Shipley MJ, Rose G, Jarrett RS, Keen M. Mortality from coronary heart disease and stroke in relation to degree of glycaemia: the Whitehal study. Br.Med f 1983;287:867-70.
35 Khaw KT, Barrett-Connor E, Suarez L, Criyui M. Predictors of stroke associated mortality in the elderly. Stroke $1984: 15: 2+4-8$

6 Vessey $M P$, Lawless $M$, Yeates $D$. Oral contraceptives and stroke: findings in a large prospective study. Br.Med f 1984;289:530-1.

37 Pettiti DB, Wingerd J, Pellegrin F, Ramcharan S. Risk of vascular disease in women: smoking, oral contraceptives, noncontraceptive estrogens, and other factors. FAMA 1979;242:1150-4.

38 Alderson MR, Lee PN, Wang R. Risks of lung cancer, chronic bronchitis, ischaemic heart disease, and stroke in relation to type of cigarette smoked. ischaemic heart disease, and stroke in relation

39 Abu-Zeid HAH, Choi NW, Maini KK, Hsu P-M, Nelson NA. Relative role of factors associated with cerebral infarction and cercbral hemorrhage. A matched pair case-control study: Stroke 1977:8:106-12.

to Bell BA, Symon L. Smoking and subarachnoid haemorrhage. Br. Hed J $1979 ;:: 577-8$

41 Bell BA, Ambrose J. Smoking and the risk of stroke. Actu Neurocher 1982;64:1-7

42 Bonita R. Cigarette smoking, hypertension and the risk of subarachnoid hemorrhage: a population-based case-control study. Stroke 1986:17:831-5.

43 Fogelholm R, Aho K. Ischaemic cerebrovascular disease in young adults. Atc Neurol Scand 1973;49:415-27

4 Taha A, Ball K, Illingworth RD. Subarachnoid haemorrhage: another smoking related disease. $f R$ Soc.Med 1982;75:332-5.

45 Herman B, Leyton ACM, Van Luisk JH, Franken CWGM, Opdecoul AAW, Schulte BPM. An evaluation of risk factors for stroke in a Dutch community. Stroke' 1982:13:334-9.

46 Fogelholm R, Murros K. Cigarette smoking and subarachnoid haemorrhage: population-based case-control study. F Neurol Neurosurg Psychiatry 1987;50: $78-80$

47 Aronow W'S, Starling L, Etienne F, et al. Risk factors for atherothrombotic brain infarction in persons over 62 vears of age in a long-term health care facility. J Am (ienatr Soc 1987:35:1-3.

48 Mackay A. Nias BC. Strokes in the young and middle-aged: consequences to the family and to society. I R Coll Physicians Lond 1979;13:106-12.

49 Syrjanen J, Valtonen VV, Iivanainen M, Kaste M, Huttunen JK. Preceding infection as an important risk factor for ischaemic brain infarction in young and middle aged patients. Br.Med f 1988;296:1156-60.

50 Oleckno WA. The risk of stroke in young adults: an analysis of the contribution of cigarette smoking and alcohol consumption. Public Heulth 1988;102:45-55

51 Molgaard CA, Bartok A, Peddecord KM, Rothrock J. The association between cerebrovascular disease and smoking: a case-control studs. Néuroepidemiology 1986:5:88-94.

52 Jick H, Porter J, Rothman KJ. Oral contraceptives and non-fatal stroke in healthy young women. Ann Intern Med 1978;89:58-60.

53 Medical Research Council Working Party. MRC trial of mild hypertension principal results. Br Med f 1985;291:97-104.

54 Gill JS, Shipley MJ, Hornby RH, Gill SK, Beevers DG. A community casecontrol study of alcohol consumption in stroke. Inl $f$ Epidemiol 1987;17: control $542-7$.

55 Wannamethee $G$, Shaper AG. Men who do not drink: a report from the British regional heart study. Int f Epidemiol 1988;17:307-16.

56 Medical Reseatch Council Working Party. Stroke and coronary heart disease in mild hypertension: risk factors and the value of treatment. Br Med. 1988;296: $1565-70$

(Accepted 14 February 1989)
An interesting ceremony took place recently at a meeting of the Boston Medical Library Association, when Dr. Oliver Wendell Holmes formally presented his medical library to the Association. Dr. Holmes was president of the Association from its formation in 1875 until last year. Its library has now grown to be one of the most important in the United States. In making the presentation, Dr. Holmes delivered a very charming little address, which is printed in the Boston Medical and Surgical fournal. He briefly sketched the growth of his collection, which ranges in time from a black letter copy of Avicenna, dated 1490, to Dr. Whitla's Pharmacy, Materia Medica, and Therapeutics, dated 1889. He said, with great truth, "the most interesting parts of a miscellaneous medical library are its oldest and its newest portions. Between these is a long, dreary interval filled up by books not old enough to be curious or even rare, and not new enough to represent the existing state of knowledge. I am thinking especially of works on practical medicine." But even for some of these he had a good word-even for some of the worst of them. "Do not look with contempt on such of your old books as seem to be mere treasuries of unwisdom. The débris of broken systems and exploded dogmas form a great mound, a Monte Testaccio of the shards and remnants of old vessels which once held human beliefs. If you take the trouble to climb to the top of it you will widen your horizon, and in these days of specialised knowledge, your horizon is not likely to be any too wide." Dr. Holmes, whose name is still borne on the books of Harvard University as Emeritus Professor of Anatomy, waxed eloquent on some of his old illustrated works on anatomy. He spoke lovingly of the splendid plates of Albinus, of the folio edition of Vesalius. "The figures," he said, "in the huge volume of Spigelius will always attract attention, for the grace and beauty of the females who display their viscera as if they were their jewels and laces. These are not likely to be overlooked by the lovers of undisguised Nature and naked truth." The day of extensive private libraries dealing with the whole domain of medicine is past, and Dr. Holmes appeared disposed to adopt the views expressed by one of the librarians of the British Museum, that "there is no reason why private libraries should exist except as feeders of great public collections." Mr. Winsor, the librarian of Harvard University, qualified this opinion" as "an eminently British sentiment," and Dr. Holmes, at least, appears to consider it a sound one. "Since medicine," he said, "has run into specialties, as it did thousands of years ago in Egypt, there must be forming great numbers of private libraries, more or less complete in these particular subjects;"' by example, if not by precept, he teaches that such collections should find their way on to the shelves of great public libraries. There is much practical wisdom in his opinion that the modern practitioner who possesses a few good manuals, and takes one or more of the best medical journals, can get on with a very small library; for a working physician, he said, is generally either an "optimist satisfied with his old remedies and formulæ, or he is in a state of chronic discontent with his drugs and mixtures, and constantly on the look-out for something which will do what so many other things have promised to do and failed." Boston may well be proud of Dr. Holmes; his name is known wherever the English tongue is spoken, but to none do his writings appeal more directly than to his brethren of the great profession of medicine. To how many young men have not his cheery words and hopeful doctrines come almost as a revelation, teaching them, perhaps, more of the true aims of their art and the true spirit in which it ought to be followed than all the formal discourses of the systematic lecturers. (British Medical Fournal 1889;i:488) 